\title{
Santos Dumont no Guia politicamente incorreto da História do Brasil
}

\section{Santos Dumont in the book The politically incorrect Guide to Brazilian History}

\author{
Rodrigo Moura Visoni \\ Instituto Histórico-Cultural da Aeronáutica | RJ
}

\begin{abstract}
RESUMO Este artigo apresenta uma análise crítica do capítulo referente a Alberto Santos Dumont no livro Guia politicamente incorreto da História do Brasil, de Leandro Narloch, publicado em 2009 e que se tornou recordista de vendas no mercado editorial brasileiro. No capítulo citado, são evidenciados erros, afirmações infundadas e conceitos equivocados, de modo a alertar leitores e educadores quanto às impropriedades do texto.
\end{abstract}

Palavras-chave Santos Dumont - erros - História do Brasil.

\begin{abstract}
This article presents a critical analysis of the chapter referent to Alberto Santos Dumont in the book The politically incorrect guide to Brazilian History, from Leandro Narloch, published in 2009, that became a best selling in the Brazilian market. In the mentioned chapter, errors, unproven statements and common misconceptions are highlighted, in order to alert readers and educators about the text improprieties.
\end{abstract}

Keywords Santos Dumont - errors - Brazilian History.

\section{Introdução}

0 Guia politicamente incorreto da História do Brasil - obra que se propõe a revisar o que tradicionalmente se conta a respeito de alguns episódios e personagens da História do Brasil -, do jornalista Leandro Narloch, foi publicado pela editora Leya em 2009. 0 livro, originalmente, dividia-se em nove capítulos: Índios, Negros, Escritores, Samba, Guerra do Paraguai, Aleijadinho, Acre, Santos Dumont e Comunistas. A segunda edição, de 2011, revista e ampliada, acrescentou mais dois capítulos, um referente aos bandeirantes e outro relativo ao período monárquico. 0 autor do "guia" admite que "também houve acréscimos e correções que se revelaram necessários depois de uma leitura mais

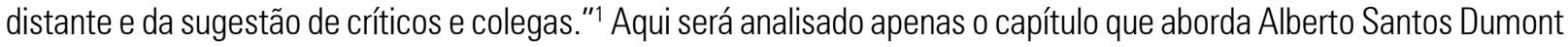
(1873-1932), o Pai da Aviação. 


\section{Alberto Santos Dumont}

No Guia politicamente incorreto da História do Brasil, Narloch escreve:

No processo de fabricação de um espírito nacional, é normal que se inventem tradições, heróis, mitos fundadores e histórias de chorar, que se jogue um brilho a mais em episódios que criam um passado em comum para todos os habitantes e provocam uma sensação de pertencimento. Se este país quer deixar de ser café com leite, um bom jeito de amadurecer é admitir que alguns dos heróis da nação eram picaretas ou pelo menos pessoas do seu tempo. ${ }^{2}$

Um dos heróis brasileiros que o autor tenta desmistificar, para, segundo ele, ajudar o Brasil a "amadurecer", é Alberto Santos Dumont, inventor e aeronauta mineiro que ganhou fama mundial no começo do século 20 com as prodigiosas façanhas aéreas que realizou em balões, dirigíveis e aviões, e cujo nome figura desde 26 de julho de 2006 no Livro dos Heróis da Pátria, em Brasília.

Pioneiro excepcional, Santos Dumont consagrou-se como um dos maiores propagadores da aeronáutica no mundo: promoveu a socialização do voo criando aeronaves pequenas e baratas, instituiu e quebrou recordes e realizou as primeiras provas públicas do voo aerostático dirigido e do voo em aeródino motorizado. Ele arriscou a vida constantemente testando as aeronaves experimentais que inventava, até conseguir modelos aperfeiçoados, com o que estimulou 0 progresso da humanidade; por esses motivos, é considerado um autêntico herói nacional.

Desmistificações podem estimular o senso crítico e ser extremamente úteis ao processo de aprendizagem. Contestações às versões oficiais da história, desde que bem fundamentadas, costumam revelar dados inéditos, ser exemplos de boas pesquisas e bastante instigantes.

A tentativa de desmistificação de Santos Dumont empreendida por Narloch, porém, foi extremamente infeliz. 0 autor acabou cometendo erros grosseiros e, em vez de extinguir mitos, apenas contribuiu para a disseminação de novos absurdos.

\section{Os erros do capítulo concernente a Santos Dumont}

Na primeira edição do Guia politicamente incorreto da História do Brasil, os erros existiam desde a primeira linha do texto alusivo a Santos Dumont, em que era informado que o famoso aviador era paulista, e não mineiro. Tal engano, que poderia haver sido evitado com uma revisão minimamente cuidadosa, foi corrigido na segunda edição, mas a situação pouco melhorou. Persistem ainda diversos trechos problemáticos, que serão agora comentados, na ordem em que aparecem:

a) Nos anos de paz, otimismo e inovação que alegraram a França no começo do século 20, enquanto os irmãos Lumière inventavam o cinema e os expressionistas inovavam a pintura, Santos Dumont encantava a capital do mundo com os balões. Provou que as estruturas movidas a hidrogênio ou ar quente poderiam ser dirigíveis e tornou propriedade pública o direito de alguns de seus inventos, permitindo que qualquer pessoa copiasse os projetos de graça.

Santos Dumont não provou que estruturas movidas a ar quente poderiam ser dirigíveis. Ao que se saiba, ele nunca voou num balão a ar quente, apenas em balões inflados a hidrogênio ou gás de iluminação. Os chamados "dirigíveis termais" só foram inventados em 1973, pelo balonista escocês Don Cameron. 
b) Infelizmente, entre as conquistas do brasileiro não se inclui a descoberta do avião. Na verdade, é um pouco infantil insistirmos que Santos Dumont inventou o avião. 0 crédito dessa descoberta é obviamente dos irmãos Orville e Wilbur Wright.

Primeiramente, é incorreto falar em "descoberta" do avião; o avião não foi descoberto, uma vez que não existia na natureza, pois se trata de um artefato tecnológico. 0 termo adequado é "invenção".

Ao contrário do que Narloch afirma tão peremptoriamente, os critérios para se creditar a autoria de um invento não são óbvios. Patentes costumam ser citadas como provas de invenção, mas esse é um critério legal, cujas condições e direitos variam de um país para outro. Muitas vezes, cientistas e inventores patenteiam projetos sem haver construído protótipos, enquanto outros constroem protótipos sem cuidar do devido patenteamento. 0 poeta francês Hortensius-Emile Charles Cros (1842-1888), por exemplo, criou um fonógrafo funcional pouco antes do célebre inventor estadunidense Thomas Edison (1847-1931) reproduzir a voz humana em 1877, mas era pobre e não podia sequer pagar as taxas inerentes ao registro da patente, de modo que depositou os planos do invento, assinados e selados, na Academia Francesa de Ciências. A despeito disso, até hoje Edison é conhecido popularmente como o grande e único inventor do fonógrafo. ${ }^{3}$

Na verdade, não raro, frequentemente até, um mesmo invento é desenvolvido de forma independente e quase simultânea por pesquisadores diferentes, em lugares diversos. Em geral, isso ocorre quando a atenção de um número considerável de investigadores é direcionada para um mesmo problema e as precondições tecnológicas estão disponíveis para o surgimento da nova tecnologia. ${ }^{4}$ No caso da invenção do avião, a história registra os nomes de vários precursores: o francês Clément Ader (1841-1925), os alemães Gustav Albin Weisskopf (1874-1927) e Karl Jatho (1873-1933), 0 dinamarquês Jacob Christian Hansen Ellehammer (1871-1946), entre outros. A disputa pelo título de primeiro aviador é complexa e não se resume a Santos Dumont e aos irmãos Wright.

c) Os dois fabricantes de bicicletas dos Estados Unidos voaram antes, voaram mais e contribuíram muito mais para a indústria aeronáutica que o inventor brasileiro.

Será mesmo? Santos Dumont iniciou voos em balões no ano de 1897 - quatro anos antes dos irmãos Wright começarem a voar planadores. Ao longo desses quatro anos, o brasileiro acumulou milhares de horas de voo, revolucionou os conceitos construtivos dos aeróstatos empregando materiais mais leves que os em voga na época, inventou e patenteou na França um novo tipo de motor e construiu o primeiro hangar com portas de correr, inovação adotada no mundo inteiro. ${ }^{5}$ Portanto, em 1900, quando os Wright dedicavam-se apenas a estudos teóricos de aviação, Santos Dumont já era um aeronauta profissional e experiente, com importantes contribuições para a indústria aeronáutica. Posteriormente, em 1909, o Demoiselle, inventado por ele, tornou-se o primeiro avião industrializado, sendo vendido pela firma Clément-Bayard por 7.000 francos a unidade. ${ }^{6}$

Sequer pode-se dizer que os dois fabricantes de bicicletas precederam Santos Dumont no voo motorizado, ao qual aderiram apenas em fins de 1903. Cinco anos antes, Santos Dumont já realizava voos em balões alongados dotados de motores a gasolina. Foi apenas no voo de aeroplanos que os Wright antecederam Santos Dumont.

Quanto às contribuições dos Wright para a indústria aeronáutica, são quase inexistentes. Os aviões fabricados por eles eram instáveis e difíceis de pilotar, e logo começaram a perder o seu diferencial tecnológico. Já na década de 1910, fabricantes concorrentes substituíram a torção de asa, inventada pelos Wright, por ailerões, e passaram a usar uma única hélice na frente em vez de duas na traseira. No lugar dos controles operados por alavancas, típicos dos aeroplanos Wright, as aeronaves rivais começaram a usar manches únicos, muito mais simples, que facilitavam a movimentação para frente e para os lados, além de rodas em vez de patins, por dispensarem trilhos e um pilão de lançamento. Os biplanos Wright rapidamente se tornaram obsoletos e em 1915 deixaram de ser produzidos. ${ }^{\text {? }}$

d) 0 Flyer I usa correntes de bicicleta, madeiras de construir casas e, exatamente como os aviões do futuro, hélices, um motor a gasolina e asas levemente curvas. 
De fato, o Flyer, o primeiro aeroplano motorizado dos irmãos Wright, testado e destruído em 17 de dezembro de 1903, possuía hélices, motor a gasolina e asas curvas; o que Narloch não diz neste trecho é que o Flyer, contrariamente aos aviões do futuro, possuía patins no lugar de rodas. Há, inclusive, uma carta de Orville Wright a Charles Allen Munn (1881-1924), editor da Scientific American, datada de 30 de junho de 1908, em que ele escreveu:

Pessoalmente, penso que as máquinas aéreas do futuro decolarão de trilhos, ou com a ajuda de dispositivos especiais. O sistema de rodas pneumáticas, agora usado na Europa, não se provou satisfatório, exceto em campos extensos, e provavelmente será mais fácil arranjar trilhos pequenos que campos extensos. ${ }^{8}$

0 tempo mostrou que Orville estava errado. Além disso, o Flyer era biplano e instável nos eixos transversal e longitudinal, por possuir leme profundor dianteiro e as asas inclinadas para baixo, dispostas em diedro negativo. Essa máquina não pode ser considerada representativa da configuração do avião moderno. 0 primeiro avião moderno, monoplano e estável, foi o № 19 de Santos Dumont, que voou 200 m em novembro de 1907. ${ }^{9}$

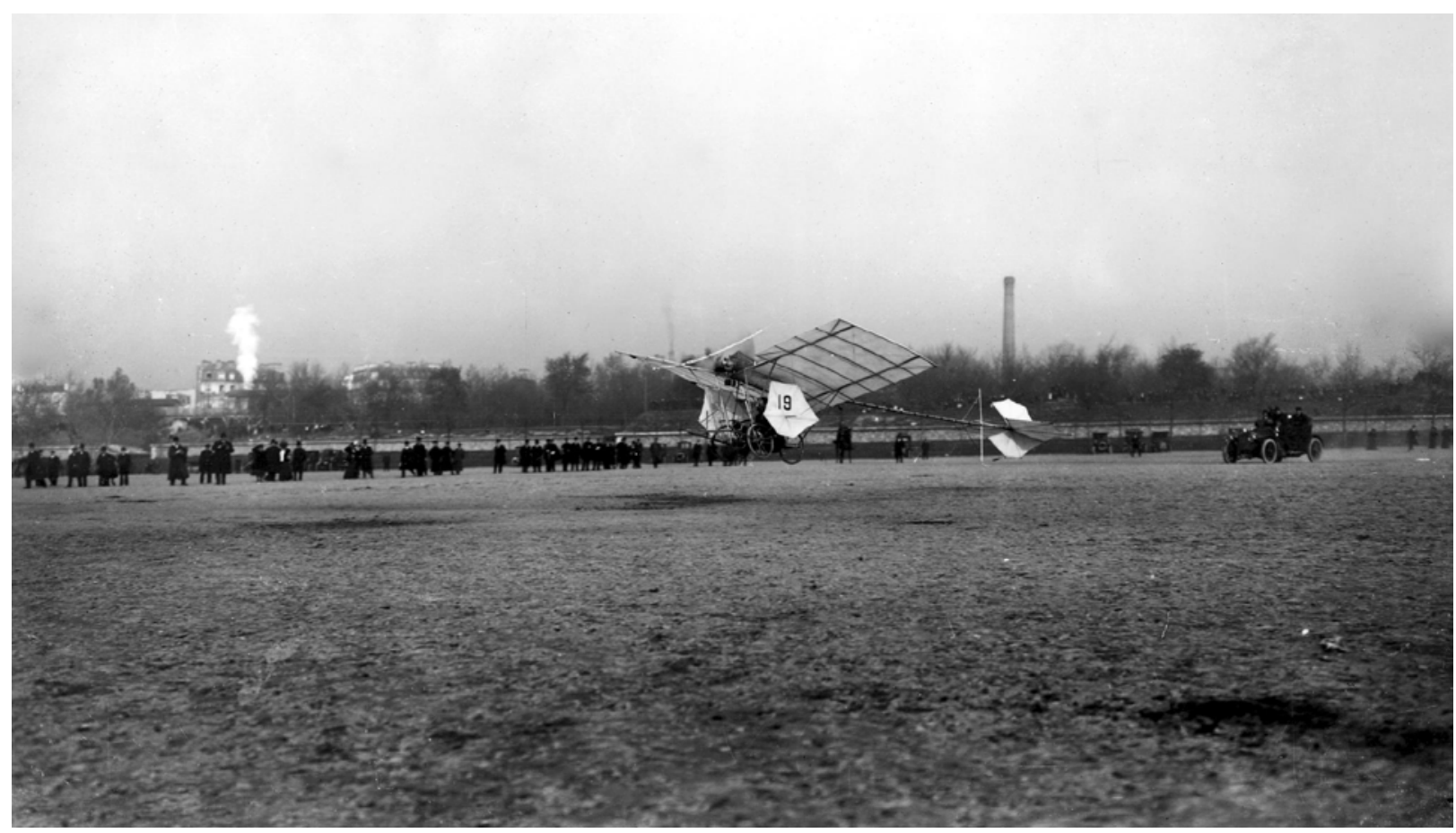

Fig. 1. 0 primeiro avião moderno: o No 19 de Santos Dumont, fotografado em pleno voo em Issy-les-Molineaux (Altos do Sena, França), no dia 17 de novembro de 1907. Crédito: Musée de l'Air et de l’Espace / Le Bourget.

e) Na mesma época [1903], Santos Dumont mal imagina que pode sair do chão com um aparelho desprovido de bolsas de ar quente.

Sem dúvida, Santos Dumont sabia que podia sair do chão com aparelhos desprovidos de bolsas de ar quente; afinal, ele voava em balões inflados com hidrogênio ou gás de iluminação. E, num artigo que publicou em junho de 1902, ele chegou mesmo a anunciar o advento do avião:

No início do próximo ano, tentarei aplicar no ar os princípios da aviação propriamente dita, sujeitando minhas aeronaves a uma evolução contínua. Na mesma proporção em que eu aumentar a extensão dos planos inclinados, simetricamente dispostos à direita e à esquerda, reduzirei a superfície do envelope de seda envernizada e, consequentemente, o volume de hidrogênio em relação à potência do motor. Assim, 
espero diminuir gradualmente a função do hidrogênio, tornando secundária a sua importância que, agora, é primária, e depois suprimir completamente o uso do gás. O dirigível haverá então se tornado um avião na absoluta acepção da palavra, e espero que algum dia nós vejamos tal acontecimento. Esse dia, sem dúvida, não está muito distante, mas o avião será atingido somente por meio da evolução, fazendo o dirigível passar por uma série de transformações análogas às metamorfoses pelas quais a crisálida se torna a borboleta. ${ }^{10}$

f) Enquanto, nos Estados Unidos, os irmãos Wright voam em aparelhos motorizados com asas levemente curvadas, 0 brasileiro constrói o dirigível-ônibus. Trata-se de um balão com dez cadeiras enfileiradas. 0 aparelho nunca decolou com mais de uma pessoa e não deixou legado nem para o balonismo nem para a aviação moderna.

0 correto seria dizer que o dirigível № 10 nunca decolou com mais de um passageiro. 0 Instituto Histórico e Geográfico Brasileiro conserva a fotografia de uma ascensão de Santos Dumont no No 10 com um homem identificado no verso como sendo o príncipe Roland Bonaparte, o que contabiliza duas pessoas. A identificação, contudo, pode estar errada, uma vez que, na imprensa da época, só foram encontrados registros de ascensões do inventor nessa aeronave com o cônsul dos Estados Unidos em Portugal, Charles Page Bryan (1856-1918), e com as senhoritas Mackey e Taylor. As três ascensões ocorreram no mesmo dia, 19 de outubro de 1903, e os convidados subiram cada um por vez. ${ }^{11}$

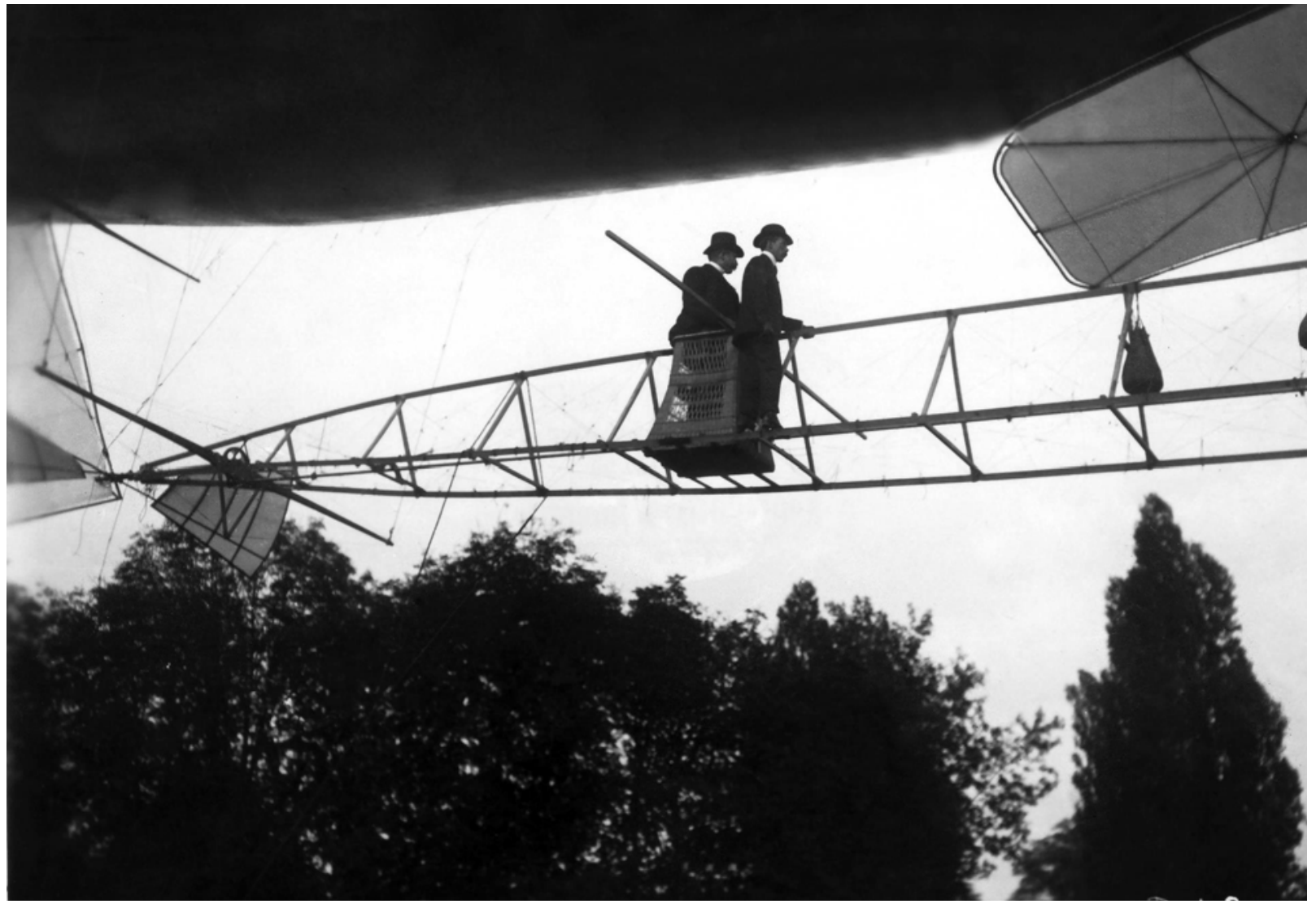

Fig. 2. Alberto Santos Dumont com passageiro (provavelmente Charles Page Bryan) a bordo do No 10, em outubro de 1903. Crédito: Instituto Histórico e Geográfico Brasileiro.

Ademais, a asserção de Narloch de que o $N^{0} 10$ não deixou nenhum legado nem para o balonismo nem para a aviação moderna, é incorreta: por anos, os dirigíveis de Santos Dumont exerceram influência nos projetos de outros inventores; um deles, o estadunidense Lincoln J. Beachey (1887-1915), que voou em 1910 numa aeronave claramente inspirada nos modelos de Santos Dumont. 


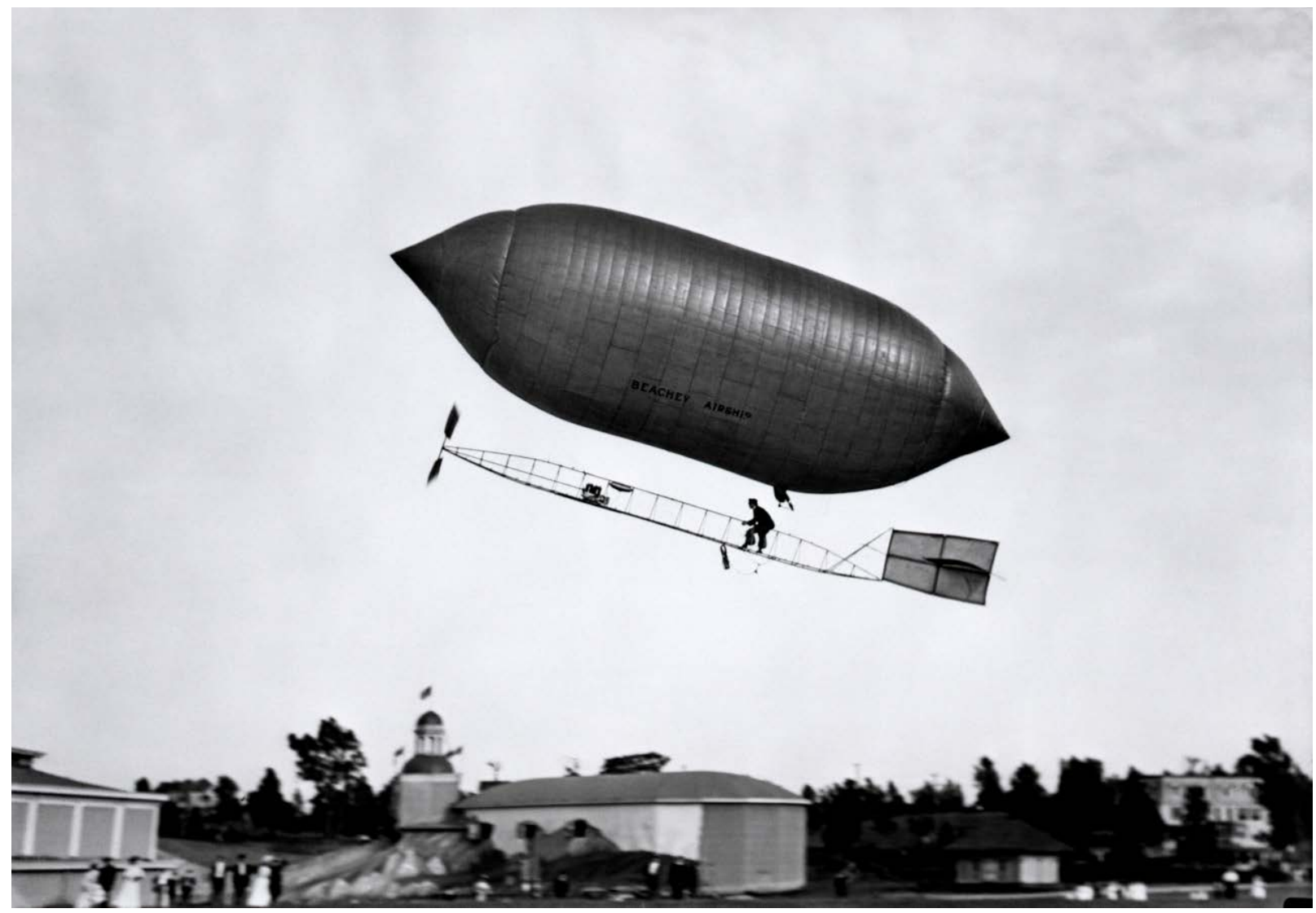

Fig. 3. Lincoln Beachey durante um voo em 1910, nos Estados Unidos. A aeronave possuía uma quilha em treliças copiada dos dirigíveis de Santos Dumont construídos a partir de 1901. Fotografia de H. Armstrong Roberts. Crédito: Corbis.

g) Santos Dumont custou a se convencer de que os balões de ar quente não eram o futuro do transporte aéreo.

Isso não é verdade. De 1898 a 1905, Santos Dumont voava em dirigíveis inflados com hidrogênio ou gás de iluminação; apenas em 1904 ele investiu num luxuoso balão misto de ar quente e hidrogênio, o $N^{\circ}$ 13, com o qual tencionava permanecer semanas na atmosfera. Além disso, num artigo que publicou em 1905, ele explicou que considerava certas formas de aeroplanos motorizados viáveis e que, se havia trabalhado até então com balões alongados, isso se deveu unicamente porque desejava navegar logo nos ares, sem mais demora, e para o próprio prazer:

Não tenho nada a opor aos aeroplanos providos de motores; há mesmo certas formas de mais pesados que considero eventualmente possíveis e até prováveis. E, se eu estivesse na liderança de uma grande estação experimental de navios aéreos, com um material ilimitado e operários à minha disposição, eu fabricaria logo, lado a lado, uma dúzia de tipos aéreos diferentes, porque sempre estive e ainda estou convencido de que só a experiência será nosso verdadeiro guia na conquista do ar. Se, em minhas próprias experiências, mantive até aqui balões alongados, é unicamente porque eu desejava navegar logo nos ares, sem mais demora, e para meu próprio prazer. ${ }^{12}$

h) 0 Número 13 é o projeto de um balão enorme, uma casa flutuante. Seria um aparelho híbrido, movido a ar quente e gás hidrogênio, que ficaria no ar por dias seguidos. 0 projeto era um perigo: o gás hidrogênio é um combustível muito potente, usado hoje em dia em foguetes e ônibus espaciais. Advertido pelos amigos sobre a possibilidade de o hidrogênio explodir com a chama que aquecia o ar, Santos Dumont cancelou o projeto antes mesmo de apresentá-lo. 
Santos Dumont não precisava ser advertido por ninguém para saber que o gás hidrogênio é inflamável. Além de ter noções de química, ele conhecia perfeitamente o caso de Pilâtre de Rozier (1754-1785), morto ao tentar atravessar o Canal da Mancha em um balão misto, vítima de uma combinação que devia reforçar, por ar aquecido, o gás hidrogênio. 0 brasileiro preveniu-se contra essa possibilidade colocando os fogareiros do $N^{0} 137 \mathrm{~m}$ abaixo da cavidade gasosa. A aeronave não voou porque, em 31 de dezembro de 1904, durante a regulagem da suspensão, no momento mais delicado da operação, uma rajada de vento atingiu o balão dentro do hangar em que estava abrigado, deixando o envelope torcido e rasgado. ${ }^{13}$ Santos Dumont acabou doando o invólucro ao Aeroclube da França em 1906.14

i) Veio então o Número 14. 0 projeto original desse aparelho também era um híbrido - meio balão, meio avião. Uma bolsa de hidrogênio anexa ao avião aliviava o peso de toda a estrutura. Como o balão tirava o equilíbrio das asas, Santos Dumont resolveu eliminá-lo (também por causa da insistência dos amigos de que balão era coisa do passado).

0 projeto original do № 14 era o de um dirigível de $186 \mathrm{~m}^{3}$, com o qual Santos Dumont fez voos na praia de Trouville em agosto de $1905 .{ }^{15}$ Depois, em julho de 1906, ele acoplou o balão desse dirigível, modificado, a um aeroplano, e chamou o híbrido de 14-bis ("14 de novo"), por estar reutilizando o balão $N^{\circ} 14 .{ }^{16}$

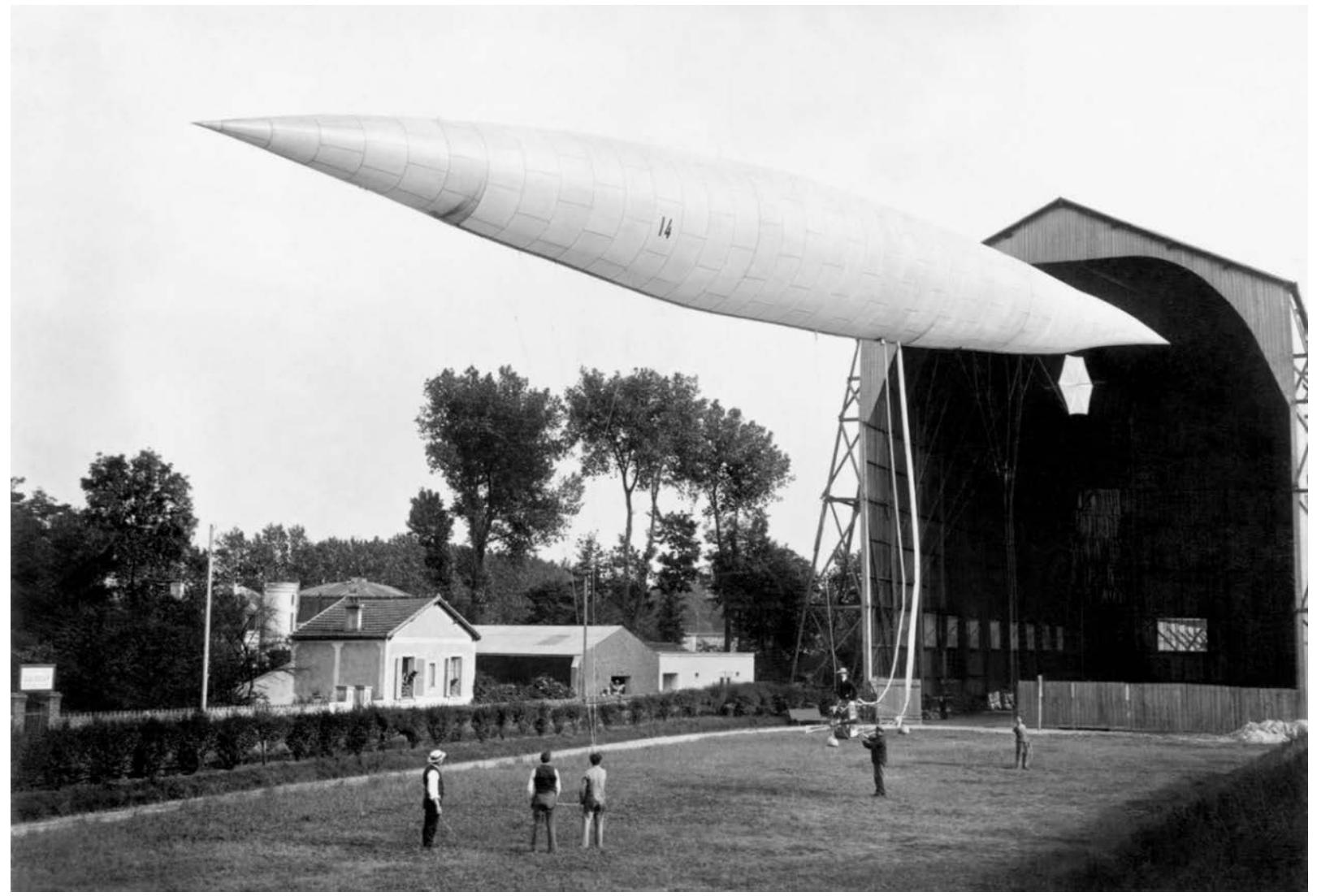

Fig. 4. 0 No 14 original, testado no parque do Aeroclube da França (Saint-Cloud, Altos do Sena), em 12 de junho de 1905. Crédito: Museu Paulista da Universidade de São Paulo. 


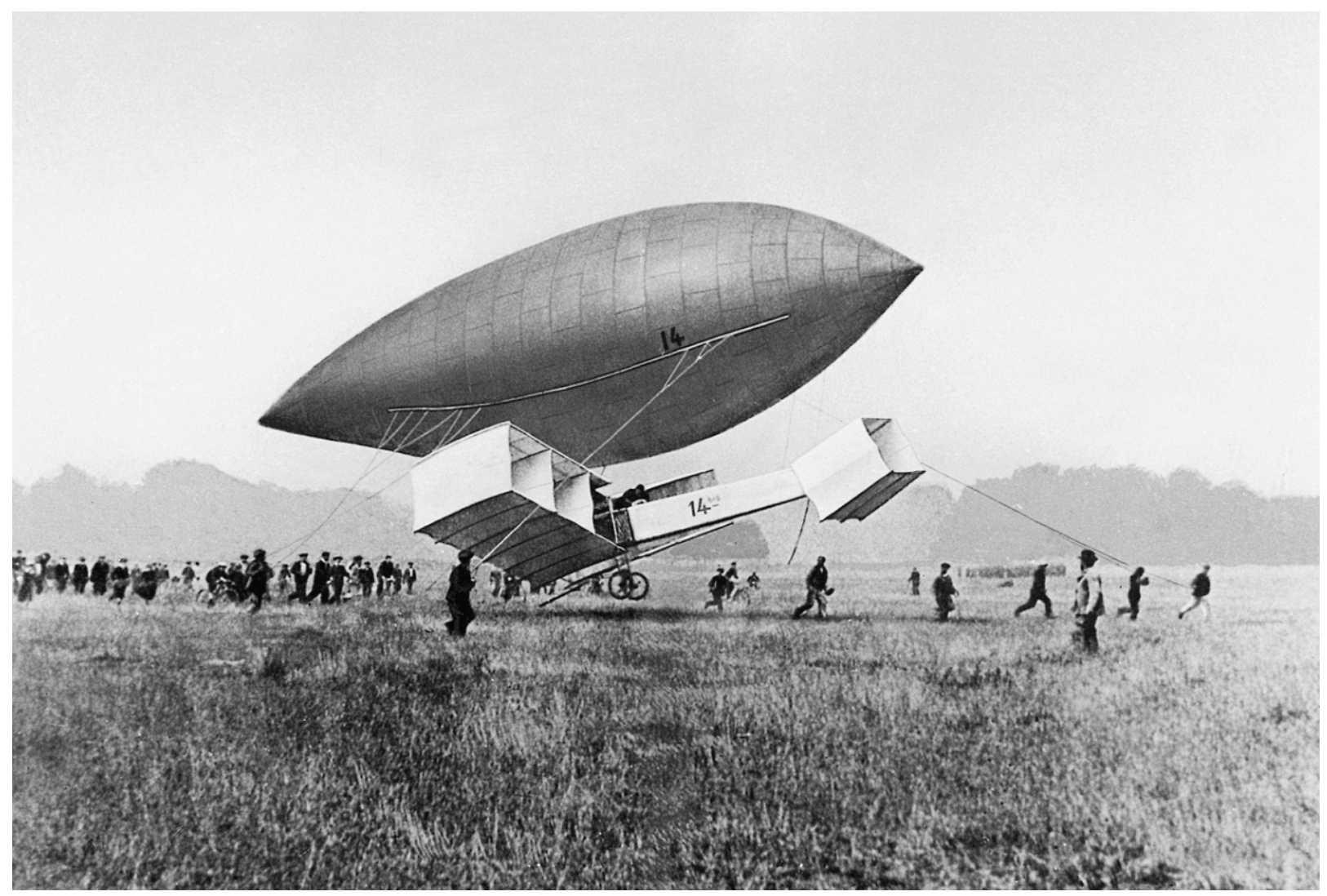

Fig. 5. Salto do 14-bis no campo de Bagatelle (Paris, França), em julho de 1906. Crédito: Smithsonian Institution.

0 aeróstato facilitava a decolagem, reduzindo o peso efetivo do aeroplano, mas, devido ao grande volume, gerava arrasto e impedia o avião de desenvolver velocidade. Santos Dumont retirou o balão e, para compensar o aumento de peso, instalou um motor de $50 \mathrm{cv}$ no lugar do de $24 \mathrm{cv}$ de que estava se valendo até então. Chamou o avião de Oiseau de Proie ("Ave de Rapina"). ${ }^{17}$ Esse avião foi bastante modificado ao longo de 1906, a ponto de poder ser classificado, modernamente, em: Oiseau de Proie I, que saltou $7 \mathrm{~m}$ em setembro, caracterizado por se apoiar em três rodas ${ }^{18 ;}$; Oiseau de Proie II, que voou $60 \mathrm{~m}$ em outubro, com apenas duas rodas no trem de pouso ${ }^{19}$; e Oiseau de Proie III, que voou 220 m em novembro de 1906, com aerofólios octogonais entre as asas. ${ }^{20}$ Houve ainda o Oiseau de Proie $I V$, que voou $30 \mathrm{~m}$ em abril de 1907 e que se particularizou por possuir aerofólios quadrangulares entre as asas. ${ }^{21}$ Diversos jornais da época, contudo, e, por vezes, o próprio inventor, costumavam se referir a todos esses modelos, indistintamente, como 14-bis.

j) O herói brasileiro só voaria mais uma vez com o 14-Bis, em abril de 1907. Depois de um voo de 30 metros de distância, a máquina se desequilibrou bruscamente e bateu no chão. A asa esquerda despedaçou-se. É instigante imaginar Santos Dumont exatamente nesse momento. Após meses tentando tirar o aparelho do chão e mantê-lo equilibrado no ar, ele se vê dentro de uma geringonça defeituosa e quebrada. Em silêncio e secretamente, deve ter percebido a verdade dolorosa: o 14-Bis não voava. No máximo, dava uns pulinhos.

Narloch se contradiz claramente nesse trecho: começou admitindo que o avião de Santos Dumont voou $30 \mathrm{~m} \mathrm{e}$ terminou dizendo que o avião não voava, só pulava. Mas qual a diferença entre um salto e um voo? Narloch não esclarece.

Quer Narloch concorde ou não, os voos de Santos Dumont com o Oiseau de Proie III, em 12 de novembro de 1906, foram considerados válidos pela Federação Aeronáutica Internacional e estabeleceram os primeiros recordes oficiais da aviação. Além disso, os testes aerodinâmicos realizados em 1983 pelo Musée de l'Air et de l'Espace com uma réplica do avião comprovaram: a sustentação gerada pelas asas era mais do que suficiente para erguer o peso do aeroplano. Nas palavras de Pierre Lissarrague, diretor do museu aeronáutico francês: 
Cremos haver ficado demonstrado que Santos Dumont não voou por acaso. Seu avião 14-bis certamente não era dos mais simples para fazer voar. Ele, no entanto, o conseguiu, e se não pôde ultrapassar seu recorde de $220 \mathrm{~m}$, é porque ele se deparou com um problema de estabilidade lateral inerente à fórmula escolhida e inextricável com os meios da época. Ele permanece, contudo, o primeiro a haver conseguido, à custa de energia e de uma rara intuição, voar de maneira sustentada diante de uma comissão de controle oficial, convocada para isso. ${ }^{22}$

\section{k) Os franceses esqueceram Santos Dumont quando conheceram os Wright.}

Isso é uma mentira. Depois dos voos de Wilbur Wright na França, em 1908, os franceses ergueram dois monumentos em homenagem a Santos Dumont: o ĺcaro de Saint-Cloud, inaugurado em 19 de outubro de 1913, comemorativo do voo histórico de doze anos antes do dirigível $N^{\circ} 6$, que valeu a Santos Dumont o Prêmio Deutsch, e o marco de Bagatelle, inaugurado em 12 de novembro de 1924, celebrativo dos primeiros voos de Santos Dumont em avião, realizados dezoito anos antes, que marcaram 0 início dos recordes oficiais na aviação. ${ }^{23}$

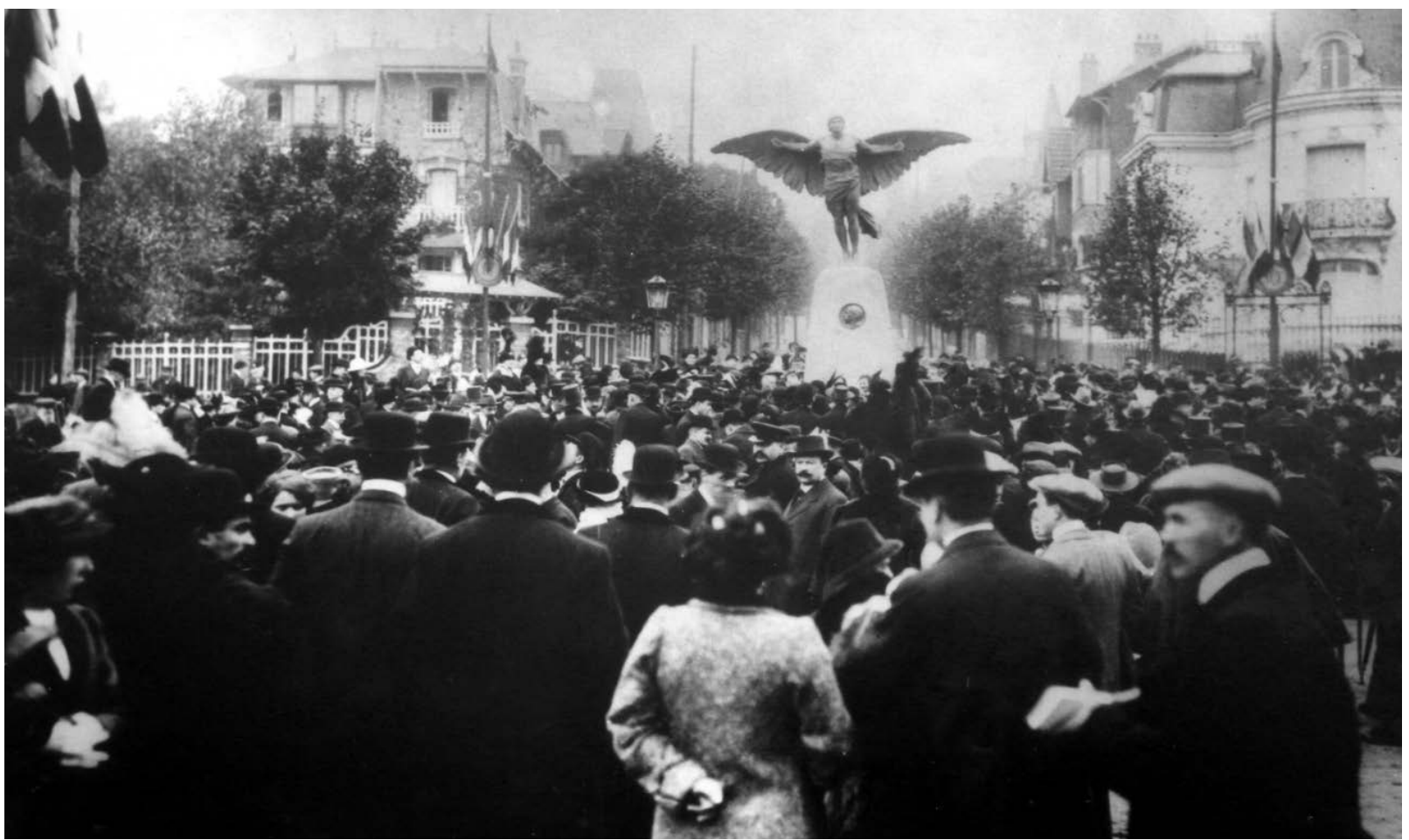

Fig. 6. Inauguração do Ícaro de Saint-Cloud, em 19 de outubro de 1913 (Paris, França). Crédito: Instituto Histórico-Cultural da Aeronáutica.

\section{1) Quando a notícia do voo de Santos Dumont chegou aos Estados Unidos, os irmãos Wright deram de ombros.}

Outra inverdade. Prova-o uma carta que Wilbur Wright encaminhou ao capitão francês Ferdinand Ferber (18621909) logo após o voo de 220 m de Santos Dumont, ocorrido em 12 de novembro de 1906:

\section{Caro capitão Ferber:}

Meu irmão Orville e eu tomamos conhecimento, por uma correspondência de Paris publicada no New York Herald, que o público francês apreciou grandemente um voo de $220 \mathrm{~m}$ em linha reta de Santos Dumont, num aeroplano de sua construção. Ficaríamos muito satisfeitos de conhecer notícias exatas sobre as experiências de Bagatelle, e estamos certos de que o senhor fará para nós um relatório fiel dos ensaios 
e uma descrição da máquina voadora, acompanhada de um esquema. Já tivemos a oportunidade de ver, numa gravura do New York Herald, que o aeroplano repousa na terra sobre três rodas, e nós deduzimos que é então necessário a Santos Dumont correr num campo extenso e uniforme para conseguir decolar. Com o pilão de lançamento que empregamos, Orville e eu saltamos diretamente no ar, com a velocidade adequada, de uma forma mais prática. Desde que os franceses julgam desempenho sensacional um voo em linha reta de apenas $220 \mathrm{~m}$, estamos certos de encontrar excelente ambiente se chegarmos a fazer exibições na França. Entretanto, a viagem e o transporte da máquina e do pilão obrigarão dois pobres mecânicos de Dayton a gastar muito dinheiro. Por isso, caro capitão Ferber, se técnicos franceses, escolhidos pelo senhor, desejarem vir a Dayton, faríamos para eles a exibição da máquina no campo vizinho, com um voo de cinco minutos, em circuito completamente fechado, cedendo-lhes opção para o desempenho e venda da máquina, mediante o pagamento de 50.000 dólares.

Sinceramente,

Wilbur Wright ${ }^{24}$

Com base nesse documento, pode-se afirmar que os irmãos Wright não só não ignoraram o voo de Santos Dumont, como se mostraram bastante interessados em saber notícias exatas a respeito das experiências de Bagatelle, além de pedirem a Ferber detalhes do avião do brasileiro, inclusive um esquema.

m) Em 1908, nas demonstrações da França, os técnicos que observaram o voo de Wilbur Wright questionaram o invento porque ele usava uma força exterior para a decolagem. 0 americano sequer discutiu. Resolveu decolar sem os trilhos e a catapulta. Voou e quebrou recordes do mesmo modo.

Esse voo sem auxílio de fato aconteceu, mas não em 1908, e sim em 24 de abril de 1909, na Itália, quando Wilbur Wright já dispunha de um motor mais potente que o de $25 \mathrm{cv}$ com o qual ele havia se exibido na França em agosto de 1908. ${ }^{25}$ Conforme noticiado pelo periódico francês L'Aérophile:

Em 24 de abril, Wilbur Wright fez uma demonstração que ele havia declarado possível, sem jamais a tentar publicamente, pelo menos na Europa. Negligenciando não somente o emprego do peso do pilão, o que ele já fez muitas vezes, mas sem usar sequer o trilho de lançamento, o que é novidade, ele se instalou no aparelho, que repousava diretamente no solo por intermédio dos seus patins. Com as hélices em movimento, o aeroplano, depois de escorregar na grama por cerca de $150 \mathrm{~m}$, se elevou facilmente, tornando a pousar e decolar com a mesma facilidade. Foram feitos nesse dia cinco voos em Centocelle, nos quais tomaram parte as senhoras Delafeld e Belville, mas os despachos não indicam claramente se essas partidas foram feitas também sem pilão nem trilhos, já que o aparelho levava uma passageira. Este modo de partida só foi possível porque um orvalho abundante cobria o gramado, tornando-o escorregadio. Com esse desempenho sensacional, Wilbur terminou suas experiências. Ele deixou Roma com Orville Wright e Katherine Wright em 28 de abril. ${ }^{26}$

Ou seja, contrariamente ao que Narloch afirmou, Wilbur Wright jamais quebrou recordes de voo decolando sem o recurso do pilão e dos trilhos de lançamento. A dispensa desses apetrechos só foi possível em Roma porque um orvalho abundante, todo ocasional, reduziu 0 atrito do chão, permitindo assim aos patins deslizarem com facilidade. Esse "detalhe" foi omitido na época pelo jornal The New York Times, que noticiou os acontecimentos deste modo:

Pelo voo que Wilbur Wright fez segunda-feira passada, em Roma, quando ele começou sem o auxílio da queda de um peso para dar à máquina o seu impulso inicial, a última das objeções da escola Voisin para o sistema Wright foi removida. Gabriel Voisin, lembrem-se, afirmou que o aeroplano Wright era apenas um brinquedo, porque a decolagem era dependente de meios mecânicos externos ao próprio aeroplano, mas a demonstração de Wilbur esta semana de que a máquina Wright pode se elevar a partir de uma decolagem corrida, anula esta crítica particular. ${ }^{27}$ 
n) 0 brasileiro não compareceu a nenhum voo de Wilbur Wright - eles jamais se conheceram. Enquanto o americano conquistava personalidades e fábricas da França, o brasileiro estava enfurnado na oficina, resolvendo problemas do N-19. A estrutura, construída a partir de 1907, ganhou o nome de Demoiselle. A máquina era quase o contrário do 14-Bis e muito parecida com o Flyer que os americanos tinham patenteado.

Essa afirmação é uma tolice completa. Dizer que o Demoiselle e o Flyer são muito parecidos só evidencia 0 elevado grau de ignorância do autor quanto ao assunto. Nem o mais ardoroso defensor dos Wright dirá que o Flyer e o Demoiselle se assemelham, em qualquer aspecto, sob pena de ser ridicularizado. Os aparelhos são perfeitamente distintos, a começar que todo Flyer é biplano, e todo Demoiselle, monoplano. Mesmo sendo o analisador um leigo, não há como confundir os aeroplanos, e é certo que um não influenciou o outro. Basta ver as fotografias das máquinas para se convencer disso.

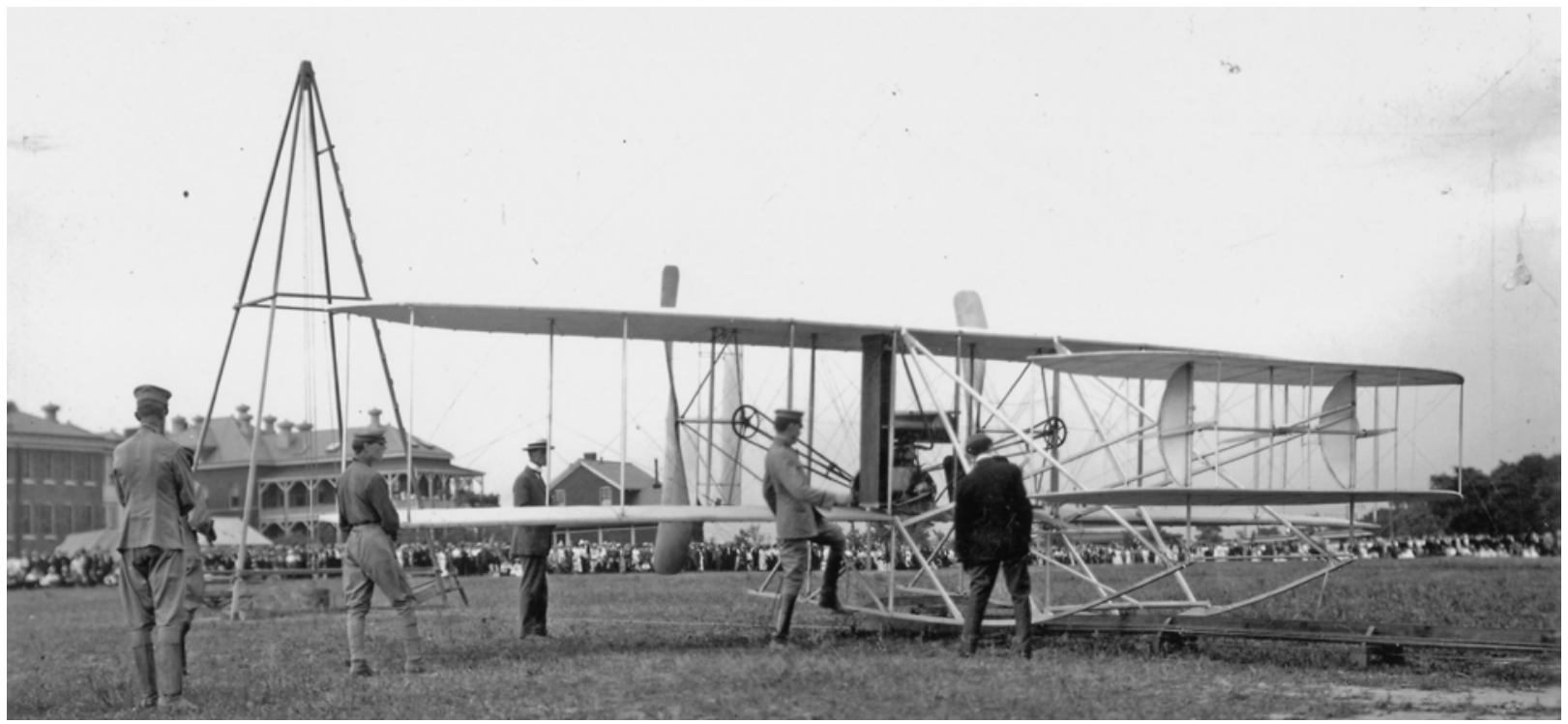

Fig. 7. 0 Wright Model A em Fort Myer, na Virgínia (Estados Unidos), no dia 27 de julho de 1909. Ao fundo, o pilão de lançamento. Crédito: Smithsonian Institution.

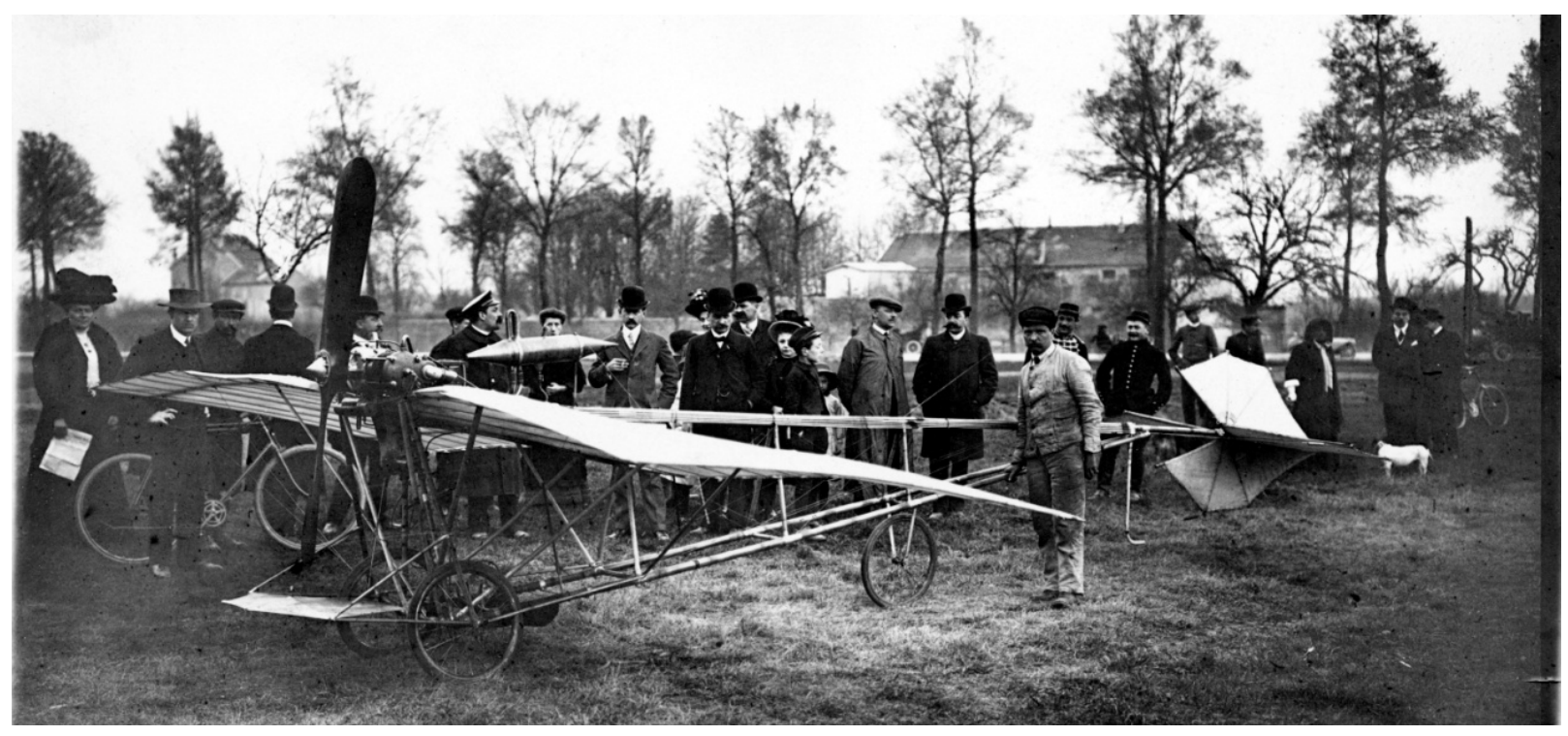

Fig. 8. 0 Demoiselle IV de Alberto Santos Dumont, na França, em meados de 1909. Crédito: Smithsonian Institution. 
Outras diferenças nítidas são: o Flyer de 1909 repousava sobre patins, possuía duas hélices traseiras e leme profundor dianteiro, ao passo que o Demoiselle da mesma época se amparava em rodas, possuía uma única hélice dianteira e leme profundor traseiro. ${ }^{28}$

o) Em 1919, sem saber que houve testemunhas e notícias dos voos dos Wright, ele [Santos Dumont] escreveu um manuscrito chamado L'Homme Mécanique.

0 "manuscrito", na verdade, é um datiloscrito, e foi redigido em 1929. É óbvio que Narloch jamais teve contato com a documentação original, que se encontra sob a guarda do Centro de Documentação da Aeronáutica (CENDOC), no Rio de Janeiro.

\section{Considerações finais}

0 objetivo do Guia politicamente incorreto da História do Brasil é interessante: desmistificar episódios e personagens da História do Brasil. Nesse tipo de estudo, no entanto, é necessário recorrer às melhores fontes de informação disponíveis, uma vez que obras de divulgação, ou páginas de internet - como as muitas referências utilizadas na bibliografia do "guia" -, não são confiáveis como fonte de pesquisa.

É recomendável consultar, sempre que possível, as fontes primárias ou originais, bem como documentos de diferentes origens e tipos (cartas, filmes, fotografias, jornais, livros) para tentar chegar a uma versão plausível, segura e condizente com os fatos. É importante, tanto no decurso quanto no fim da investigação, pedir a opinião de outros pesquisadores, discutir, conhecer pontos de vista antagônicos, reavaliar o trabalho feito. É justamente por não terem tido esse cuidado que autores amadores costumam perpetuar erros e interpretações que carecem de fundamento.

Foi o que aconteceu com Leandro Narloch. Certamente todos ou quase todos os erros cometidos por ele poderiam haver sido evitados, entre outras maneiras, se ele houvesse pedido uma apreciação prévia de especialistas em história da aviação ou de biógrafos de Santos Dumont; mas não, ele se limitou a adotar a posição de estudiosos que se coadunassem com os objetivos do livro que planejava fazer, sem se preocupar em apresentar argumentos bem embasados ou contrapartes.

0 ingresso de jornalistas no ramo historiográfico, competindo com a produção acadêmica, não é recente, e tem crescido significativamente. Os jornalistas Eduardo Bueno e José Laurentino Gomes, por exemplo, já contam com uma produção literária de cunho historiográfico volumosa, embora de teor e méritos bastante discutíveis. É com muita preocupação que se vê os livros desses autores - Narloch incluído - sendo usados indiscriminadamente como paradidáticos.

Uma das principais funções dos livros paradidáticos é diminuir a defasagem entre os últimos avanços de uma ciência e o conhecimento escolar, daí a importância desses livros serem escritos por especialistas (preferencialmente, pessoas com pós-graduação), de modo a reduzir o risco de serem transmitidas aos estudantes informações erradas e conceitos deturpados, ao contrário do que acontece atualmente, em que é comum jornalistas se dedicarem a escrever sobre temas históricos sem estarem bem informados, treinados ou devidamente assessorados para isso. 0 sucesso de vendas dos trabalhos amadorísticos resultantes, quando ocorre, é devido, em boa parte, a um público leitor acrítico e ingênuo. Trabalhos desse tipo prestam um desserviço à educação e em nada contribuem para o Brasil amadurecer - apenas apodrecer.

É possível corrigir o capítulo relativo a Santos Dumont do Guia politicamente incorreto da História do Brasil com as observações apresentadas neste artigo, mantendo a ideia central? Isso parece ser muito difícil. 0 autor precisaria reescrever o texto por inteiro e, se quiser insistir na posição inicial adotada, rejeitando tudo o que foi dito aqui, precisará compilar novos dados e apresentar outra interpretação, que conteste e supere a presente crítica em termos de 
clareza e concordância com os fatos levantados, pois não conseguirá mais convencer ninguém apenas com estudos superficiais e informações de segunda mão.

Seria mais fácil, para uma nova edição, simplesmente eliminar o capítulo referente a Santos Dumont; o livro ficaria menos ruim. Ou, então, retirar a palavra "politicamente" do título do livro, que passaria a ser Guia incorreto da História do Brasil. Assim não haveria necessidade de mexer no conteúdo.

\section{Notas e referências bibliográficas}

Rodrigo Moura Visoni é bacharel em Arquivologia pela UNIRIO e primeiro-tenente arquivista do Instituto Histórico-Cultural da Aeronáutica. E-mail: rmvisoni@ yahoo.com.br

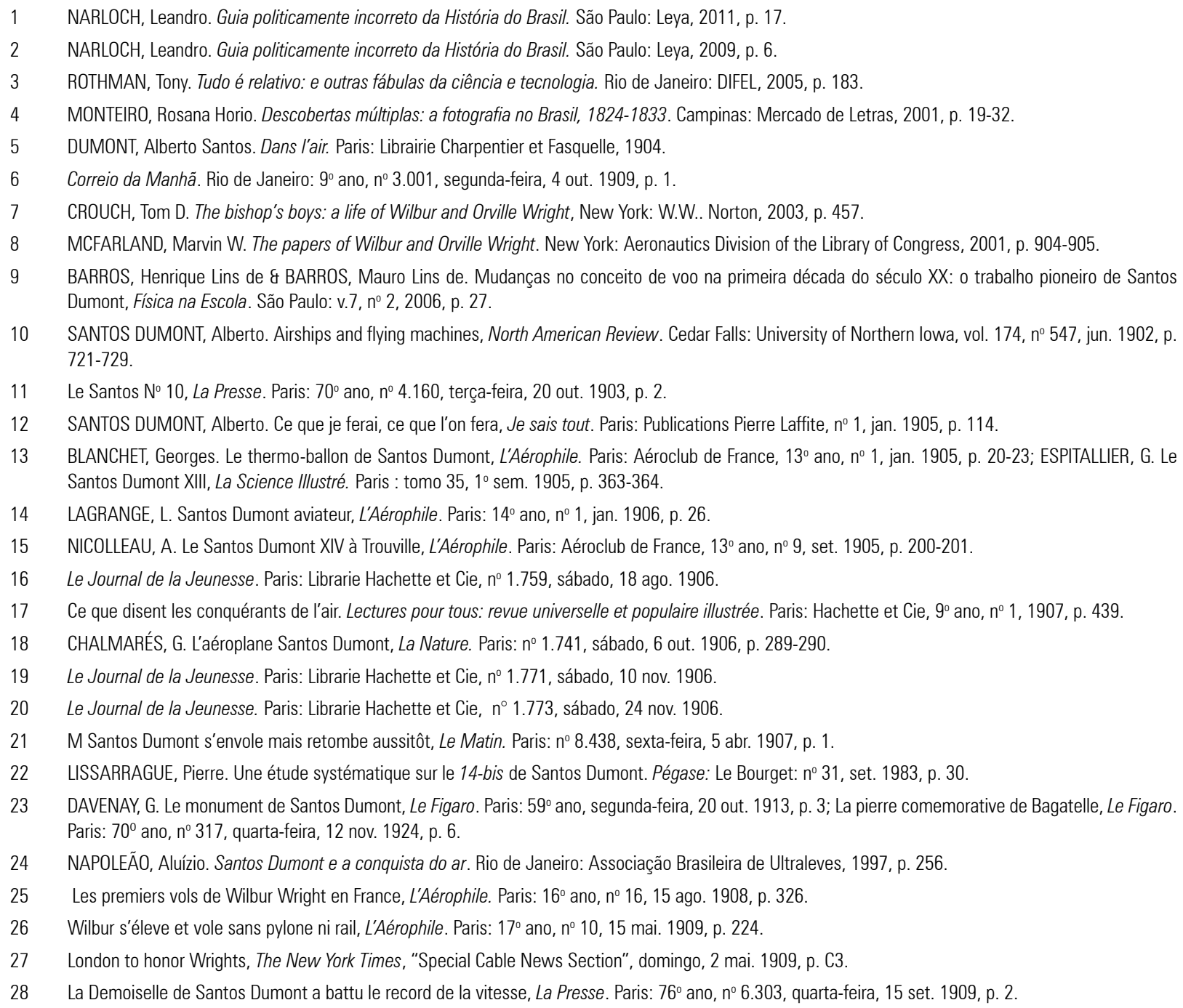

10 SANTOS DUMONT, Alberto. Airships and flying machines, North American Review. Cedar Falls: University of Northern lowa, vol. 174, n 547, jun. 1902, p. 721-729.

11 Le Santos № 10, La Presse. Paris: $70^{\circ}$ ano, nº 4.160, terça-feira, 20 out. 1903, p. 2.

12 SANTOS DUMONT, Alberto. Ce que je ferai, ce que l'on fera, Je sais tout. Paris: Publications Pierre Laffite, no 1, jan. 1905, p. 114.

13 BLANCHET, Georges. Le thermo-ballon de Santos Dumont, L'Aérophile. Paris: Aéroclub de France, $13^{\circ}$ ano, no 1, jan. 1905, p. 20-23; ESPITALLIER, G. Le Santos Dumont XIII, La Science Illustré. Paris : tomo 35, $1^{\circ}$ sem. 1905, p. 363-364.

14 LAGRANGE, L. Santos Dumont aviateur, L'Aérophile. Paris: $14^{\circ}$ ano, nº 1, jan. 1906, p. 26.

15 NICOLLEAU, A. Le Santos Dumont XIV à Trouville, L'Aérophile. Paris: Aéroclub de France, 13º ano, nº 9, set. 1905, p. 200-201.

16 Le Journal de la Jeunesse. Paris: Librarie Hachette et Cie, nº 1.759, sábado, 18 ago. 1906.

17 Ce que disent les conquérants de l'air. Lectures pour tous: revue universelle et populaire illustrée. Paris: Hachette et Cie, $9^{\circ}$ ano, no 1, 1907, p. 439

18 CHALMARÉS, G. L'aéroplane Santos Dumont, La Nature. Paris: nº 1.741, sábado, 6 out. 1906, p. 289-290.

19 Le Journal de la Jeunesse. Paris: Librarie Hachette et Cie, nº 1.771, sábado, 10 nov. 1906.

20 Le Journal de la Jeunesse. Paris: Librarie Hachette et Cie, n 1.773, sábado, 24 nov. 1906.

21 M Santos Dumont s'envole mais retombe aussitôt, Le Matin. Paris: $n^{\circ}$ 8.438, sexta-feira, 5 abr. 1907, p. 1.

22 LISSARRAGUE, Pierre. Une étude systématique sur le 14-bis de Santos Dumont. Pégase: Le Bourget: nº 31, set. 1983, p. 30

23 DAVENAY, G. Le monument de Santos Dumont, Le Figaro. Paris: $59^{\circ}$ ano, segunda-feira, 20 out. 1913, p. 3; La pierre comemorative de Bagatelle, Le Figaro. Paris: $70^{\circ}$ ano, $n^{\circ} 317$, quarta-feira, 12 nov. 1924, p. 6.

24 NAPOLEÃO, Aluízio. Santos Dumont e a conquista do ar. Rio de Janeiro: Associação Brasileira de Ultraleves, 1997, p. 256.

25 Les premiers vols de Wilbur Wright en France, L'Aérophile. Paris: 16º ano, no 16, 15 ago. 1908, p. 326.

26 Wilbur s'éleve et vole sans pylone ni rail, L'Aérophile. Paris: $17^{\circ}$ ano, no 10, 15 mai. 1909, p. 224.

27 London to honor Wrights, The New York Times, "Special Cable News Section", domingo, 2 mai. 1909, p. C3.

28 La Demoiselle de Santos Dumont a battu le record de la vitesse, La Presse. Paris: 76º ano, nº 6.303, quarta-feira, 15 set. 1909 , p. 2.

[Recebido em Agosto de 2014. Aprovado para publicação em Janeiro de 2015] 